\title{
Stepping into the Era of Personal Big Data: a Roadmap to the Design of a Personal Digital Life Coach
}

\author{
Nuno M. Garcia, Nuno Pombo, Torsten Braun, Francisco Flórez-Revuelta, Ivan \\ Chorbev, Susanna Spinsante, David Lamas, Rossitza Goleva \\ Submitted to: Journal of Medical Internet Research \\ on: July 05, 2016
}

\begin{abstract}
Disclaimer: ( $)$ The authors. All rights reserved. This is a privileged document currently under peer-review/community review. Authors have provided JMIR Publications with an exclusive license to publish this preprint on it's website for review purposes only. While the final peer-reviewed paper may be licensed under a CC BY license on publication, at this stage authors and publisher expressively prohibit redistribution of this draft paper other than for review purposes.
\end{abstract}




\section{Table of Contents}

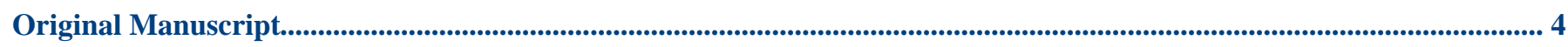




\section{Stepping into the Era of Personal Big Data: a Roadmap to the Design of a Personal Digital Life Coach}

Nuno M. Garcia, Ph.D.; Nuno Pombo, Ph.D.; Torsten Braun, Ph.D.; Francisco Flórez-Revuelta, Ph.D.; Ivan Chorbev, Ph.D.; Susanna Spinsante, Ph.D.; David Lamas, Ph.D.; Rossitza Goleva, Ph.D.

\section{Corresponding Author:}

Nuno M. Garcia, Ph.D.

Phone:

Fax:

Email:ngarcia@di.ubi.pt

\section{Abstract}

The increased availability of devices that can record every aspect of a person's life will allow the recording of a large amount of data that will be primarily useful for that particular user. These devices and their data will place each and every one of us at the doorstep of the era of personal big data. Using this data, in a not so distant future, we will be able to set a personal digital life coach, a digital platform that will act at an individual level, but also considering a global interaction, not only as a social networking tool, but as a platform that will profit from the individual experiences of its users. This position paper focuses on the identification of the milestones that will mark the creation of such a software and hardware platform, by exploring the opportunities and challenges that it poses to the computer science researchers, and how such a solution can be designed to be a user-adoptable lifestyles monitoring and training tool.

(JMIR Preprints 05/07/2016:6315)

DOI: https://doi.org/10.2196/preprints.6315

\section{Preprint Settings}

1) Would you like to publish your submitted manuscript as preprint?

(a) Please make my preprint PDF available to anyone at any time (recommended).

(b) Please make my preprint PDF available only to logged-in users; I understand that my title and abstract will remain visible to all users.

$\checkmark$ (c) Only make the preprint title and abstract visible.

(d) No, I do not wish to publish my submitted manuscript as a preprint.

2) If accepted for publication in a JMIR journal, would you like the PDF to be visible to the public?

(a) Yes, please make my accepted manuscript PDF available to anyone at any time (Recommended).

(b) Yes, but please make my accepted manuscript PDF available only to logged-in users; I understand that the title and abstract

(c) Yes, but only make the title and abstract visible (see Important note, above). I understand that if I later pay to participate in <a href=" 


\section{Original Manuscript}




\title{
Stepping into the Era of Personal Big Data: a Roadmap to the Design of a Personal Digital Life Coach
}

\author{
Nuno M. Garcia ${ }^{1,2,3}$, Nuno Pombo ${ }^{1,2}$, Torsten Braun ${ }^{4}$, Francisco Florez- \\ Revuelta $^{5}$, Ivan Chorbev ${ }^{6}$, Susanna Spinsante ${ }^{7}$, David Lamas ${ }^{8}$, Rossitza \\ Goleva $^{9}$ \\ ${ }^{1}$ Universidade da Beira Interior, Faculty of Engineering, Computer Science Department, \\ Covilhã, Portugal \\ ${ }^{2}$ Instituto de Telecomunicações, ALLab - Assisted Living Computing and Telecommunications \\ Laboratory, Covilhã, Portugal \\ ${ }^{3}$ Universidade Lusófona de Humanidades e Tecnologias, Lisbon, Portugal \\ ${ }^{4}$ University of Bern, Bern, Switzerland \\ ${ }^{5}$ Faculty of Science, Engineering and Computing, Kingston University, Kingston upon Thames, \\ United Kingdom \\ ${ }^{6}$ Faculty of Computer Science and Engineering, Ss. Cyril and Methodius University, Skopje, R. \\ of Macedonia \\ ${ }^{7}$ Universita' Politecnica delle Marche, Ancona, Italy \\ ${ }^{8}$ Institute of Informatics, Tallinn University, Tallinn, Estonia \\ ${ }^{9}$ Department of Communication Networks, Technical University of Sofia, Sofia, Bulgaria \\ ngarcia@di.ubi.pt, ngpombo@ubi.pt, \\ braun@inf.unibe.ch, F.Florez@kingston.ac.uk, \\ ivan.chorbev@finki.ukim.mk, s.spinsante@univpm.it, \\ drl@tlu.ee, rig@tu-sofia.bg
}

\begin{abstract}
The increased availability of devices that can record every aspect of a person's life will allow the recording of a large amount of data that will be primarily useful for that particular user. These devices and their data will place each and every one of us at the doorstep of the era of personal big data. Using this data, in a not so distant future, we will be able to set a personal digital life coach, a digital platform that will act at an individual level, but also considering a global interaction, not only as a social networking tool, but as a platform that will profit from the individual experiences of its users. This position paper focuses on the identification of the milestones that will mark the creation of such a software and hardware platform, by exploring the opportunities and challenges that it poses to the computer science researchers, and how such a solution can be designed to be a user-adoptable lifestyles monitoring and training tool.
\end{abstract}


Keywords: Personal Digital Life Coach, Mobile Application, Smart portable devices, Sensors, Usability, Cooperative Algorithms, Personal Big Data.

\section{Introduction}

The creation of a "Personal Digital Life Coach" is still a somehow distant goal. Yet, the creation of such a piece of digital craftsmanship would be of extreme help, not only for those of us who will someday be older and ill, but also for the older and healthy and, why not, for the young (ill or healthy). In fact, this would allow each individual to profit from the advices of a digital omnipresent "friend", "who" would "know" one’s habits and life style, one’s ambitions, goals, and limitations, and would allow its user to get expert advices on each step of her/his life. The use of commas in the previous sentence serves to illustrate how hard it can be to describe this project without using some type of personification.

A Personal Digital Life Coach (or PDLC for short) will monitor its user's actions and activities, providing the ability to recognize the user's state of mind, and to propose measures that not only will allow the user to achieve his/her stated goals, but also will act as an intermediate health and wellbeing agent, between the user and his/her immediate care givers. But, apart from this, a PDLC can be devised as a larger platform, resulting from the combination of several autonomous, complementary and cooperative systems and sensors, as discussed in the following sections.

The PDLC platform here envisioned is therefore one of many possible scenarios. This paper addresses what would be the possible architectures, requisites, sensory capabilities, and interfaces towards the individual user and the community of PDLC users.

Before describing the steps that need to be undertaken to devise such a system, it is convenient to elaborate on the advantages that such system may bring to the user. As it is widely known, many diseases are the result of unhealthy lifestyles. Paramount of unhealthy lifestyles is the tobacco addiction (or other addictions), and sedentary life styles, such as the ones that do not integrate an adequate amount of exercise, physical, or mental and social interaction. Among such diseases one can find those related to obesity, including some types of diabetes, cardiovascular related diseases, including high blood pressure, depression, and others, such as lung and larynx cancer [1-4]. The treatment of lifestyle related diseases is responsible for a large share of national healthcare budgets worldwide, and this has become a concern for policy makers and governments [5-7], especially in developed countries.

Yet, the advantages don't restrain to unhealthy users who may wish to train healthier lifestyles. The availability of such platforms would enable everyone to enter a new era of Big Data. This new area, named Personal Big Data, will consist in the data that is generated by, and relevant to each of our independent living experiences, data that can be stored, and further analyzed and used to help not only each individual but also the members of the community, with the goal of enhancing their own lives.

This paper describes one of the possible concepts for such a platform, a first step towards the Personal Big Data, and one of the possible roadmaps towards its construction in a, hopefully, not so distant future. The definition of the identified stakeholders, primary and secondary, is also discussed. The remainder of this paper is organized as follows: section 2 identifies the possible stakeholders of a PDLC solution, and the primary and secondary initial meta-requirements; section 3 discusses the possible architectures for a PDLC solution; section 4 presents a proposal for a roadmap, and section 5 terminates this paper with relevant conclusions.

\section{Background}

\subsection{Motivation}

Assisted Living (AAL) and Enhanced Living Environments (ELE) platforms are often focused on 
the needs of "the User", a more or less generic group, instead of being focused on the needs of a given user or a specific user profile. The generalization of solutions is increasingly less relevant as we move towards personal medicine, personal environments, and automatic and customizable solutions.

This previous statements acknowledge that a human user may live a life that is so diverse and complex, that it can be extremely complicated to fit his/her life pattern in the definition of a generic user profile. Traditional AAL approaches are often described as "the tool that does X to the users that suffer/need Y", and this is an approach that has been adequate for the old manner of living the world, what can be described as "the wheelchair approach". Wheelchairs are undoubtedly very useful devices for people who have temporary or permanent disabilities that impair their mobility, and unfortunately, often wheelchairs are the only available solution. Yet, by partially solving the mobility problem, the wheelchair can bring a completely new set of other problems that, although are of lesser importance to the user, still may need to be addressed. Also, wheelchairs are solutions that, given the alternatives, have high adoption ratios among its potential users; nevertheless, these are very often the only available solution.

Moreover, not only individual humans live complex lives, human societies are also complex and have been changing faster in the last decades [8,9], particularly in what is generally accepted as the building block of human societies, the family. The concept of family has therefore evolved, and as authors in [8] acknowledge, there is an increase in the plurality and diversity of the concept itself. The Internet and its contribution to the feeling of connectedness [10, 11] also contributes to the notion that a family is no longer just the aggregate of people who, sharing sociological bonds, share also a common life space.

If, on the one hand, the family (a concept that is also changing and has multiple interpretations) is the natural support for the individual [12], not only the fragile one, but also the one who needs advice or company, on the other hand, most western countries have also, in a complementary manner, developed some forms of social providence or welfare state, in a way that medical care and life supporting means are usually not denied to anyone who may need them. The immediate cost of the welfare to the state's treasures is not to be demised, although some argue that the reason to establish and support a welfare state is not the value of its policies, but the value of its principles. Philosophical and political issues apart, nations and governments have come to realize that they too are interested parties in the wellbeing of each individual citizen.

\subsection{Stakeholders}

Considering a PDLC as an instrumental tool for the goal of keeping one's health and wellbeing, that is shared by the person him/herself, his/her family and ultimately, the society he/she lives in, there are several stakeholders for a PDLC. As the center and as primary stakeholder, the individual is now promoted to the category of PDLC user him/herself. As secondary stakeholders, we identify the community the user is member of (that also includes relatives, friends, colleagues). As tertiary stakeholders, we have the caregivers, the health and wellbeing professionals, and, among the collective stakeholders, we have the company, the organization, and the state the user belongs to. Although this is a very linear manner of describing potential stakeholders, it must also be noted that secondary and tertiary stakeholders share a fuzzy border, as for example, family members often act as caregivers, and caregivers often become friends.

Better described forward, we will add yet another class of stakeholders who are directly interested in the success of the PDLC platform. A PDLC will be able to connect itself to the community of PDLCs, looking for better practices, sharing successes and failures, and, while doing this, the chances to find meaningful information increases with the size of the PDLC community. Therefore, alongside with secondary stakeholders, we also need to consider the PDLC users community. In Figure 1 the stakeholders are depicted, showing the fuzzy borders for stakeholder classification and 
also, the interactions among them (best seen in color). The oval shapes represent the human stakeholders: individuals are represented as an oval with a single boundary line, collective or multiple stakeholders are represented with a double boundary line. Institutional stakeholders are represented by a rounded corner rectangle, and a cloud shape represents virtual or machine stakeholders. White arrows depict the interaction between stakeholders, representing the information flows. Overlapping shapes represent the often unclear boundaries between stakeholder roles.

By representing individual, collective, general and machine stakeholders, we also acknowledge that a stakeholder is an entity whose objectives are better met if the objectives of the main stakeholder are also met.

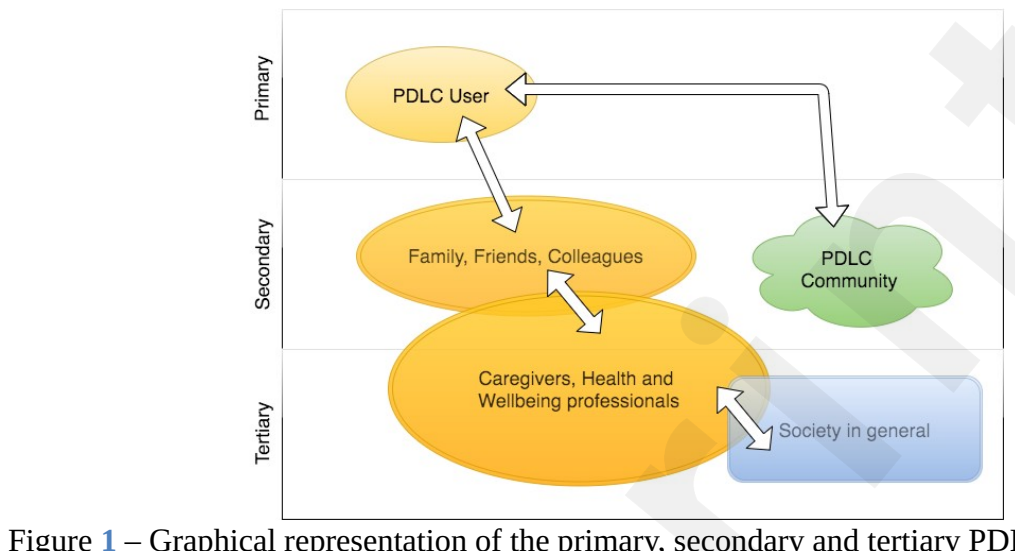

Figure 1 - Graphical representation of the primary, secondary and tertiary PDLC stakeholders.

\subsection{System macro-requirements}

Having defined the stakeholders, we can now define the primary and secondary initial macrorequirements for a PDLC, while keeping in mind that a PDLC is a platform that implies that there is a life to be lived, i.e., the user is still able, to a minimum extent, to conduct and decide on his/her daily life choices.

As primary macro-requirements, a PDLC is a tool that is able to:

1. identify a diverse range of daily activities;

2. identify patterns of behavior and detect when abnormal or unexpected behavior occurs;

3. estimate the amount of energy its user is expending on each activity;

4. assess / infer the mood of the user;

5. input and record the user's personal goals, e.g., to loose weight, to quit an addition, to work fewer hours;

6. keep track of the effective behavior and compare it with the expected behavior, given not only previous behavioral patterns but also the user's recorded goals;

7. monitor and record some of the user's vital signs, e.g., his/her electrocardiography (ECG) signal, or his/her blood pressure, or the user's amount of movement, etc.;

8. alert the immediate and secondary caregivers when an anomaly occurs, e.g. a life threatening event;

9. keep the collected data in the strictest confidential manner, only disclosing data that it is allowed to, to the relevant stakeholders;

10. integrate error safe mechanisms to assume that advices and data that the PDLC is feeding to its user are not flawed, and are not potentially dangerous.

As secondary macro-requirements, a PDLC is a tool that:

1. works in a non-intrusive, user adaptable and adoptable manner;

2. allows the user to interact with it by means of natural interfaces, such as voice and gestures; 
3. interfaces with the user by voice and text (email, SMS, etc.);

4. allows the communication of relevant and authorized data with other PDLCs as a mean to reap the benefits from big data applications;

5. communicates with, or is fed by, several agents that collect data in the users devices, such as, the user's Internet home gateway router, social network feeds and/or activity report agents, the user's car computer, etc.;

6. is able to work in full compliance of national and international laws, particularly those that regulate medical devices, and those that regulate the privacy, safety and security of personal information;

7. be capable to run knowledge extraction and pattern recognition algorithms over the data aggregated from a single user/patient, but also over the joint data collected from all beneficiaries with the aim of updating its classifiers, abnormality detectors, develop new advisory mechanisms, health improvement vs. illness causing patterns, etc.; Decision trees, Support Vector Machines, Deep learning approaches are only a few examples that need to be implemented;

8. provide relevance feedback from all stakeholders to take into account in order to improve classifiers and functionalities.

The definition of the stakeholders and of the macro-requirements for a PDLC allows the conclusion that there are a number of important milestones to conquer before such a solution may appear on the shelves of a digital application store.

A key requirement to fulfil is the aspect of privacy and confidentiality. Keeping someone's health records is a challenge by itself, but monitoring, storing and processing someone's entire daily routines, health and mood parameters and variations, locations, activities implies a great deal of confidence in the system by the end users. Privacy policies need to be strict and respected, while security procedures and algorithms need to be state of the art adding additional processing burden. Although data is used for general statistical and knowledge extraction purposes hence not providing personal information, specific user profiles and information needs to be well protected.

\section{Architecture for a PDLC Solution}

\subsection{Modeling the System}

The first step to enable the creation of a PDLC, is to define a system that has the following characteristics:

1. It is a computational platform with some processing power (although "some" is not a scientific expression, we still lack the techniques to estimate how much processing power a complex tobe-developed application or set of applications will need);

2. it is powerful enough to perform data storage, data fusion, data imputation, and can be connected to the Internet;

3. and also small enough that at least part of the system can be carried by its user most of the time;

4. integrates a set of sensors that can sense and identify most of the activities the user is doing, most of the time;

5. can communicate with actuators and other hardware and/or software that the user needs to interact with;

6. is modular both in terms of software components for easy upgrade and in terms of hardware components and interfaces to integrate new sensors and actuators;

7. and, last but not the least, is safe and guarantees the user that his/her data are secure and cannot be disseminated without the user's explicit consent. 
Additionally, the system will be non-intrusive, and will provide its user with services in a manner that will contribute to easy adoption. Or, in other words, the center of the solution is the user, not the technology, nor the applications.

In the line of what Weiser has defined as ubiquitous computing [13], a PDLC will fail if it does not have enough data, or if the data it used was not correctly weighted, and these errors need to be acknowledged and foreseen in the planning of the tool.

Out-of-the-shelf smartphones and smart-watches can presently perform most of these tasks, with the added bonus that most of the times the device is carried by its user. But this is not yet a closed issue, as there are still too many variables to address, for example, there are different usage styles for smartphones, i.e. while it seems clear that some users will keep the smartphone in the pocket of their trousers or jackets, others will likely carry it in their purses or bags. Another class of devices that can complement a smartphone sensing and computational task are the smart-watches and other smartwearables, that can sense a wide variety of biosignals and communicate them to a relevant computational platform [14].

\subsection{Data Management}

A PDLC will be a system that can detect not only the expectable events on a person's daily life, but also the abnormal events or the undesirable events, making it possible to, in view of a user's expected pattern of behavior, and his/her announced and defined goals, provide the user with expert advice to correct, immediately or later on, the unadvisable behavior.

Considering the amount of data a PDLC has to collect and process, it becomes evident that several degrees of efficiency and complexity for a PDLC must be defined. The simplest one will be a standalone application, probably installed in a smartphone or some other wearable device that performs a basic level of monitoring and allows for some basic life-coaching decisions. In fact, there are already several systems that monitor the user while he/she exercises, and allow him/her to keep track of the energy expenditure, some including also social networking features [15]. A more complex solution will probably be a multi-agent software, spanning several of the user's hardware and/or software interaction points, and allowing the collection of the fused data in a central system where decisions are taken and advices are conveyed to the user. By hardware interaction points we refer to the hardware that supports the user's activities, e.g., a smartphone, of course, but also, e.g., the television set or home entertainment box, the home router, or the user's car. By software collection points we propose the monitoring software that allows the system to monitor browsing history, electronic messaging of different types, agenda management, and so on.

The data for this collection may be stored and processed locally, in the case of the basic architectures, or may be stored and processed in some form of cloud. Of relevance will be the fact that a complex PDLC will have the ability to share, in a secure, safe and confidential manner, the data from its users with other systems, allowing for the adoption of algorithms for big data processing.

A PDLC will also be able to perform data imputation as a manner to fill in the gaps in the collected data, either because the sensors were busy for some other application, or because there were errors in the transmission, or because of noisy or lossy environments in the collection or transmission stages. Also, a PDLC will also be able to perform data fusion, as a mean to minimize uncertainty regarding the identification of a given user's mood or a particular user's task. Moreover, a PDLC should also provide summarization techniques aiming at extracting the most relevant sample from the entire collected data for analysis, visualization and/or report purposes.

An interesting two-level approach to process the variety of sensor data and other data streams has been presented in StudentLife [24]. Raw sensor data are first collected and analyzed, resulting in behavioral classifiers such as activity, sleeping, conversation. Classified activities are then used for applications analyzing for example the mental health of students. 
As mentioned before, the PDLC must assume that erroneous data or advices conveyed to its user may cause him/her harm, and therefore the PDLC must integrate not only the necessary fail safe mechanisms to avoid that, but also mechanisms that allow frequent feedback from its user, to enable the confirmation or infirmation of the results of its processes. These mechanisms, and also the mechanisms that will support decision-making, data imputation, and data fusion may be founded in artificial intelligence algorithms and techniques.

Figure 2 shows the components of a PDLC. The PDLC ecosystem will be based in two main components: the PDLC applications that will reside in the user's PDLC-enabled smart-devices, shown as the central hexagon with blue background (best seen in color), and the PDLC community, shown as a cloud with several small hexagons. While the interaction between the PDLC and its community will be detailed forward, it's worth mentioning that the PDLC will place queries to the PDLC Community asking for best practices, and will receive replies with information regarding these best practices.

Also visible in the scheme in Figure 2, is the feed system that will allow the PDLC to contribute with its own data to the PDLC Community. The component that will be responsible for summarizing this data is the User Profiling application, represented as an arrow label in the scheme. This application will summarize the user context, i.e. what the user has been doing and what are the moods of the user over a period of time that still needs to be defined, being this period probably a function of the type of user, and integrate this user context with the user's goals and user progress information, to create a dynamic map of the user's progress and a profile radar of the user's goals. This data will feed the PDLC community, and its evolution over time will allow the PDLC community to assess the efficiency of the advices provided by each personal PDLC.

Figure 2 also shows that the PDLC will be based on three principal components: the Activities of Daily Living Identification (ADLI) [14, 15], the Human Emotions Identification (HEI) [16, 17] and finally, a component capable of managing, recording, and assessing the progress of the user towards his/her goals (shown as trapezes inside the central hexagon).

What Figure 2 does not show are the interactions between the different pieces of hardware that will host the PDLC software components. As to allow a better understanding of how the different smartdevices in the user's environment can cooperate to feed data to the ADLI and the HEI modules, it's useful to name at least a few sensory streams that will be used to these purposes. Table 1 provides a non-exhaustive list of sensors and other data streams that can contribute to a specific goal.

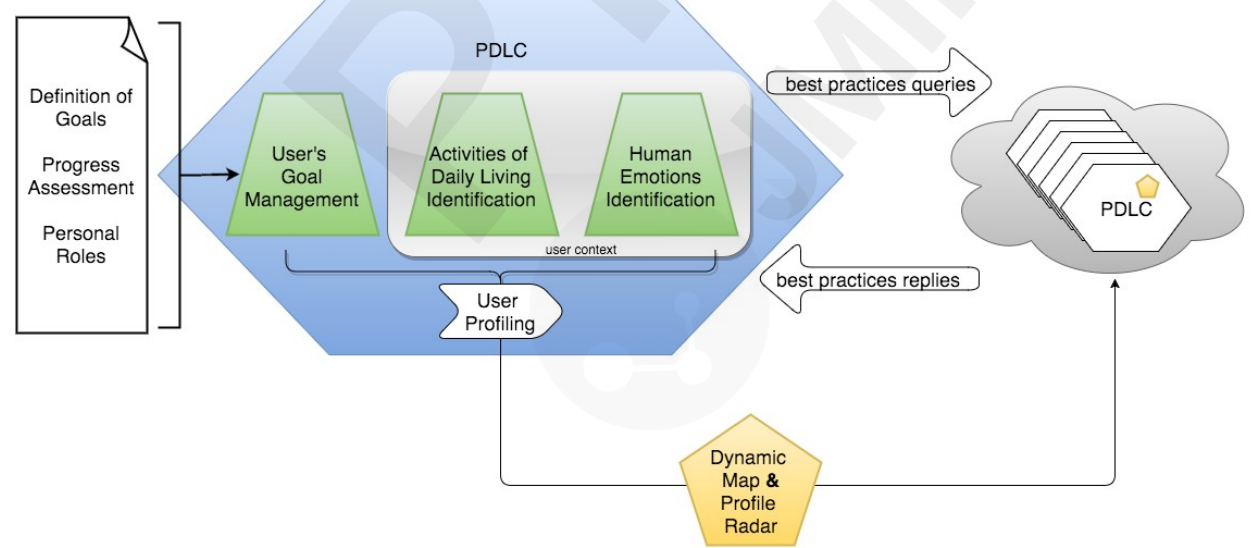

Figure 2 - Architectural view of the PDLC components.

Table 1 - Sensors and data streams that will feed the ADLI and HEI modules (non-exhaustive list).

\begin{tabular}{llll}
\hline Sensor / & Device & Contributing to & Will feed \\
Data & & \\
Stream & & \\
\hline
\end{tabular}




\begin{tabular}{|c|c|c|c|}
\hline $\begin{array}{l}\text { Accelerome } \\
\text { ter }\end{array}$ & $\begin{array}{l}\text { Smartphon } \\
\text { e, smart- } \\
\text { watch, } \\
\text { smart- } \\
\text { wearables }\end{array}$ & $\begin{array}{l}\text { Assessment of caloric } \\
\text { expenditure, definition } \\
\text { of movement patterns, } \\
\text { fall detection, location }\end{array}$ & ADLI, HEI \\
\hline $\begin{array}{l}\text { Location } \\
\text { sensors } \\
(\text { e.g.) } \\
\text { Compass, } \\
\text { GPS, Wi-Fi } \\
\text { location } \\
\text { based } \\
\text { systems }\end{array}$ & $\begin{array}{l}\text { Smartphon } \\
\text { e, smart- } \\
\text { watch, } \\
\text { smart- } \\
\text { wearables }\end{array}$ & $\begin{array}{l}\begin{array}{l}\text { Locate the user (indoor / } \\
\text { outdoor), } \\
\text { activity (e.g. } \\
\text { driving) }\end{array}\end{array}$ & ADLI, HEI \\
\hline $\begin{array}{l}\text { Microphone } \\
\text { s }\end{array}$ & $\begin{array}{l}\text { Smartphon } \\
\text { e, Smart- } \\
\text { watch }\end{array}$ & $\begin{array}{l}\text { Assessment of the user's } \\
\text { environment }\end{array}$ & ADLI, HEI \\
\hline $\begin{array}{l}\text { Web } \\
\text { browsing } \\
\text { logs }\end{array}$ & $\begin{array}{l}\text { Smartphon } \\
\text { e, } \\
\text { Computer, } \\
\text { Smart TV }\end{array}$ & $\begin{array}{l}\text { Estimation of user } \\
\text { behaviors }\end{array}$ & HEI \\
\hline $\begin{array}{l}\text { Mobile } \\
\text { phone usage } \\
\text { logs }\end{array}$ & $\begin{array}{l}\text { Smartphon } \\
\text { e }\end{array}$ & $\begin{array}{l}\text { Estimation of user } \\
\text { behaviors }\end{array}$ & HEI \\
\hline Agenda & $\begin{array}{l}\text { Computer, } \\
\text { Smartphon } \\
\text { e, online } \\
\text { accounts }\end{array}$ & $\begin{array}{l}\text { Monitoring of user } \\
\text { behaviors }\end{array}$ & HEI, ADLI \\
\hline $\begin{array}{l}\text { Smart TV } \\
\text { zapping }\end{array}$ & Smart TV & $\begin{array}{l}\text { Monitoring of user } \\
\text { behaviors }\end{array}$ & HEI, ADLI \\
\hline $\begin{array}{l}\text { File system } \\
\text { changes }\end{array}$ & $\begin{array}{l}\text { Smartphon } \\
\text { e, } \\
\text { Computer }\end{array}$ & $\begin{array}{l}\text { Monitoring of user } \\
\text { behaviors }\end{array}$ & HEI, ADLI \\
\hline $\begin{array}{l}\text { Informatio } \\
\text { n about } \\
\text { environmen } \\
\text { t (weather, } \\
\text { traffic) }\end{array}$ & $\begin{array}{l}\text { Internet, } \\
\text { social } \\
\text { networks }\end{array}$ & $\begin{array}{l}\text { Assessment of user's } \\
\text { environment }\end{array}$ & ADLI \\
\hline $\begin{array}{l}\text { Home } \\
\text { activity }\end{array}$ & $\begin{array}{l}\text { Smart } \\
\text { home } \\
\text { devices, } \\
\text { e.g., } \\
\text { sensors, } \\
\text { cameras, } \\
\text { appliances, } \\
\text { home } \\
\text { gateways }\end{array}$ & $\begin{array}{l}\text { Monitoring of user } \\
\text { behaviors }\end{array}$ & ADLI, HEI \\
\hline $\begin{array}{l}\text { Activity of } \\
\text { other users }\end{array}$ & $\begin{array}{l}\text { Internet, } \\
\text { social } \\
\text { networks }\end{array}$ & $\begin{array}{l}\text { Assessment of user's } \\
\text { environment }\end{array}$ & ADLI, HEI \\
\hline
\end{tabular}




\section{A Roadmap}

This paper describes, at a conceptual level, what would be the roadmap to design a Personal Digital Life Coach, that would act like a "best friend" for its user, giving advices and tips on the choices of his/her daily living, with the ultimate objective to allow the training of healthier and happier life styles.

Before defining one possible roadmap, it's better to detail some of the components that are depicted in Figure 2.

The overall concept, as described earlier, is simple to state, but yet not so easy to achieve. The user will state his/her goals, and the system, having in consideration the user's daily activities and the user moods, will try to change the pattern of activity to allow the user to achieve his/her goal.

Non-exclusively, the goals can be mapped into one of three categories:

- Health and wellbeing;

- Social;

- Personal / cognitive.

Moreover, these three categories can further be mapped to the five layers of the well-known Maslow pyramid of human motivations [18]. The health and wellbeing goals map primarily to the Basic needs, in a lesser extent to the Security needs and finally, somewhat to the Social (Love) needs; the Social goals map primarily to the Social (Love) needs, to a lesser extent to the Esteem needs, and finally, somewhat to the Security needs; the Personal or Cognitive goals map to the Self-actualization needs, to a lesser extent to the Esteem needs, and somewhat to the Social (Love) needs. Figure 3 depicts this correspondence, showing the original expressions used by Maslow in his seminal paper.

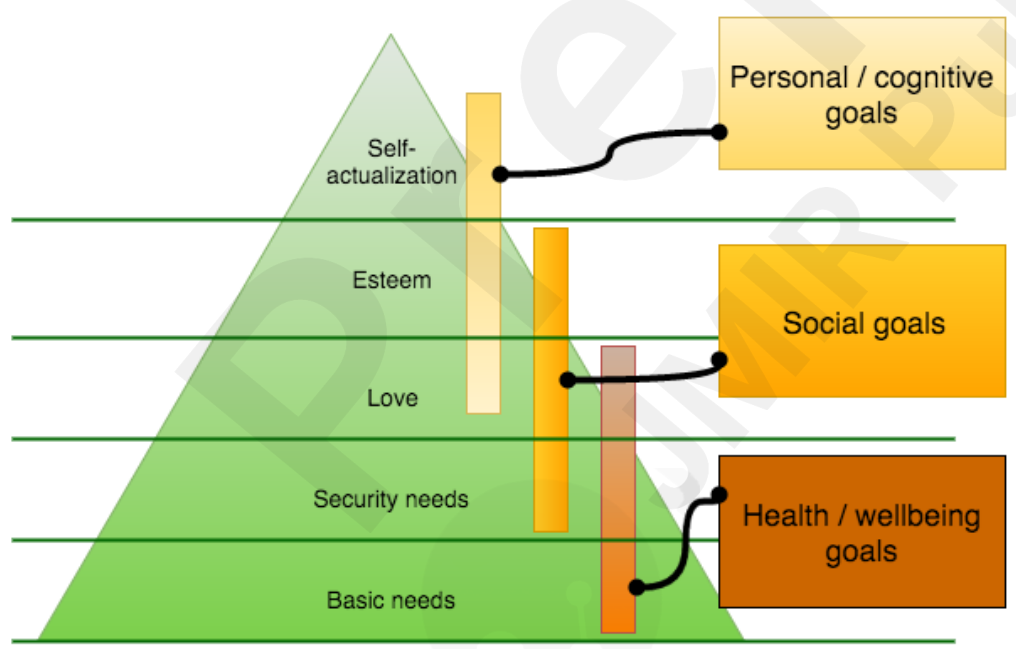

Figure 3 - Correspondence between the Maslow layers of human motivation and the levels of goals for the PDLC.

Examples of possible goals can be seen in Table 2. The list is presented without any concern regarding the feasibility of the goal nor its relevance / importance for a given user. Moreover, the possible line of action of the PDLC is suggested here merely as a hypothesis of what the PDLC could suggest regarding the aimed goal. This table also disregards the interaction of the PDLC with the PDLC Community.

To allow the correct mapping of the user context (please see Figure 2), the PDLC must be able to infer the status of the user and it's circumstance, much in the manner Ortega Y Gasset described the human experience [19]. The information about the mood of the user [20] and his/her circumstance [14] allows the PDLC to devise a map of the user's position relative to his/her goals or, if the definition of goals is absent, the user's position relative to its areas of interest and according to 
his/her own assessment, dynamic in space and time (please see Figure 2). The definition of the format of this map is one of the milestones in the roadmap for the creation of a PDLC, but one possible approach can be to use a radar map that is a snapshot in time of the user current state, and that is charted in several axes, each one registering one concrete aspect of the user's multiple areas of interest.

The user of a PDLC can take one of two possible roles (Personal Roles in Figure 2): mentee, or mentor. The default role is that of a mentee; it should be possible to allow a PDLC user to be a mentor only after his/her progress has been consistently recorded for a significant amount of time, whatever "consistently" or "significant amount of time" may mean. Being a mentee means that the system will accept as input one's goals and, having in view the profile of one's ADLs and one's moods, it will suggest changes in the user habits as to drive the user towards its goal. As an example, if one's goal is to be able to spend more time making exercise, the PDLC may suggest periodic exercises, or the enrolment in a gymnasium, or may suggest nearby sports activities (please see examples in Table 1).

Table 2 - Examples of goals, classification and possible line of action for the PDLC.

\begin{tabular}{|c|c|c|}
\hline Goal & Category & $\begin{array}{l}\text { Possible PDLC line of } \\
\text { action }\end{array}$ \\
\hline Wake up earlier & Health and WB & $\begin{array}{l}\text { Warn the user to go to bed } \\
\text { early and set the alarm clock } \\
\text { to the desired time }\end{array}$ \\
\hline $\begin{array}{l}\text { Spend more time with } \\
\text { friends }\end{array}$ & Social & $\begin{array}{l}\text { Schedule time to socialize } \\
\text { and search for friends' } \\
\text { locations in the user's social } \\
\text { network application }\end{array}$ \\
\hline Read more & Personal & $\begin{array}{l}\text { Schedule reading time at } \\
\text { appropriate times; suggest } \\
\text { books / articles / } \\
\text { newspapers the user may } \\
\text { find interesting }\end{array}$ \\
\hline Listen to music & Personal & $\begin{array}{l}\text { Warn the user about nearby } \\
\text { concerts; suggest playing } \\
\text { lists and music websites }\end{array}$ \\
\hline Travel more & $\begin{array}{l}\text { Personal } \\
\text { Social }\end{array}$ & $\begin{array}{l}\text { Warn the user about } \\
\text { promotions on travel; } \\
\text { suggest destinations based } \\
\text { on user preferences }\end{array}$ \\
\hline Learn a new skill & Personal & $\begin{array}{l}\text { Schedule learning time and } \\
\text { suggest learning } \\
\text { methodologies }\end{array}$ \\
\hline $\begin{array}{l}\text { Quit smoking (or } \\
\text { other addiction) }\end{array}$ & Health and WB & $\begin{array}{l}\text { Prepare a plan to achieve } \\
\text { this, according to medical / } \\
\text { psychological advice }\end{array}$ \\
\hline Improve eating habits & Health and WB & $\begin{array}{l}\text { Suggest eating routines, } \\
\text { based on nutritionist advice }\end{array}$ \\
\hline Do more exercise & Health and WB & $\begin{array}{l}\text { Find a gymnasium that is } \\
\text { suitable to the user (close to }\end{array}$ \\
\hline
\end{tabular}




\begin{tabular}{|c|c|c|}
\hline & & $\begin{array}{l}\text { his commuting routine) or } \\
\text { suggest exercise routines at } \\
\text { adequate times }\end{array}$ \\
\hline $\begin{array}{l}\text { Take the medication } \\
\text { at the correct times }\end{array}$ & Health and WB & $\begin{array}{l}\text { Remember the user of the } \\
\text { medication }\end{array}$ \\
\hline $\begin{array}{l}\text { Improve a } \\
\text { relationship }\end{array}$ & Social & $\begin{array}{l}\text { Schedule time to invest in } \\
\text { the relationship, keep track } \\
\text { of the user's phone activity } \\
\text { and warn the user to } \\
\text { communicate more }\end{array}$ \\
\hline $\begin{array}{l}\text { Arrive on time to my } \\
\text { meetings }\end{array}$ & Social & $\begin{array}{l}\text { Manage the user's agenda to } \\
\text { allow for travelling time, } \\
\text { warning the user when to } \\
\text { depart his current position }\end{array}$ \\
\hline Relax more & Health and WB & $\begin{array}{l}\text { Suggest frequent breaks } \\
\text { from work, suggest walks } \\
\text { and walking paths, suggest } \\
\text { adequate music }\end{array}$ \\
\hline
\end{tabular}

Being a mentor will bring humans back into the loop of life coaching. A start-up social network that combined artificial intelligence with human feedback called Aardvark was bought in 2010 by Google, to be inactivated in 2011 [21, 22]. Using Aardvark, a user could ask "what are the best winter tires for Portugal?", and the replies would arrive a couple of minutes later (or days) when the human users replied to the query. The match between questions and users was made by comparing relevant keywords in the questions with areas of interest and expertise stated by the user. The figure of a PDLC mentor would do something similar, either anonymously, or not. If anonymously, the reply of the mentor would be integrated in the system as a form of recommendation sent through the PDLC Community (not shown in Figure 2). Anonymously, a subject that agrees to serve as a mentor would confirm on infirm a suggested line of action for an undisclosed user, regarding a specific goal. Alternatively, the user could appoint her/his friends Alice and Bob (e.g.) to act as mentors, and the PDLC would invite them to use the system to help the user achieve the aimed goals. An additional usefulness mechanism would be implemented to rank the user's compliance with the suggestion, to rank the mentor's suggestions and to rank the overall proposed line of action. This rank will feed the PDLC Community databases. The rank can also be used to improve the quality of the PDLC by adopting machine learning mechanisms, i.e. by analyzing whether calculated recommendations were useful or not.

Additionally, after the user has defined his/her goals and the system is engaged in a line of action toward the realization of these goals, it is crucial to assess the progress of the user. This can be done in three different manners:

- using self-assessment scores,

- asking for assessment from the user's mentors, possibly also using grading scores, and

- through the changes in the user's behavior, as inferred by the PDLC.

This feature, considering the participation of mentors or not, is depicted in Figure 2 as Progress Assessment. The assessment of the advancement of a user's goal can be made not only in qualitative terms, i.e., how far has the user progressed towards his/her goals, but also in quantitative terms, i.e., how fast is the user progressing. These two types of assessment will allow the PDLC Community to further rank the best practices for a given goal.

Finally, the roadmap for the development of a PDLC platform includes the following steps:

1. the development of software that can be installed in personal mobile devices, such as smartwatches or smartphones, and that is able to identify daily activities of a user; 
2. the development of software that can recognize patterns of daily activities and also identify meaningful deviations from these patterns;

3. the development of agents that can reside in the hardware the user interacts with, and that can send to a central processing application their relevant usage data;

4. the development of software that can integrate all the data a user generates into meaningful insights of his/her personal life style, by integrating the recording of a user's dynamic map and profile radar;

5. the development of software that, given the identification of the user's behavior, can create acceptable behavior alternatives that allow the user to achieve his/her previously defined lifestyle objectives.

This roadmap also includes, at some point:

1. the identification of some of the user's emotions, e.g. by means of sensors and usage data patterns;

2. the identification and association of the user's data to the relevant caregivers, family and friends;

3. the capability to "understand" clusters of data from these users, into a social behavior scenario, allowing the realization of the social integration of the user;

4. the capability to integrate failsafe mechanisms and frequent user interaction mechanisms that allow the user to confirm or infirm the algorithm's output, and therefore, establish a feedback loop that enables additional algorithm output correctness.

Some of these milestones are not yet at our reach, and others may have a long research time ahead. But from the authors' perspective, a PDLC would be a very useful application. This opinion seems to be underlined by the European Commission, who has recently launched, a program in Personalised Coaching for well-being and care of people as they age [23]. As stated in the call document [23], “(...) Proposals should develop a proof of concept of radically new solutions for a personalised "virtual coach", building upon intelligent ICT environments, access to relevant physiological and behavioral data, new forms of accessible interaction based on tangible user interaction concepts, open platforms and emotional computing. Usability and ease of user interaction should be essential design elements of the "coach" (...)".

\section{Conclusions}

The notion of having a "friend in the pocket", or in the wrist, or in the computer, being this computer some wearable computational platform is a risk, primarily because users are not keen in digitalizing their entire life, but also because we still have to assess what is the real level of benefits or prejudice that computational applications have brought to human development. As always, not all humans are alike, and if for some of them a PDLC would be a significant help, to others it would just be meaningless.

The PDLC will inaugurate and take advantage of the coming era of personal big data and will have to address all the new challenges related to recording, managing, and accessing this information, possibly, while the user travels to different parts of the world.

The PDLC will also embody a shift from the patient centered solution to the health and well-being centered solution, collecting data from healthy subjects and allowing to infer hidden cause-effect relationships, including crossing location based data with weather and emotions and health, and others less obvious, as food, drinking, social events and so on. Taking on the personal big data for each user, but also on the collections of personal big data from the user community, the PDLC will allow us, in the future, to discover the cause-effect relationships, not only while the user is sick or 
fragile, but also, and more importantly, while the user is still healthy, just before he/she gets sick. This paper presented the concept of a Personal Digital Life Coach, an application or set of applications that will allow a user to receive advices and information that allow him/her to train his/her lifestyle into a more healthier and maybe happier one.

As discussed previously, it is the authors' belief that we still have a significant way to go to master all the technologies that will allow us to build a PDLC. Yet, as reinforced by the European Commission's plans, this will likely happen before 2020.

\section{Acknowledgments}

The authors acknowledge the contribution of COST Action IC1303 AAPELE Algorithms, Architectures and Platforms for Enhanced Living Environments, and COST Action IC1307 IV\&L Integrating Vision and Language.

Authors affiliated with the Instituto de Telecomunicações also acknowledge the funding for the research by means of the program FCT project UID/EEA/50008/2013. (Este trabalho foi suportado pelo projecto FCT UID/EEA/50008/2013).

\section{References}

[1] L. Lien, Å. Sagatun, S. Heyerdahl, A. J. Søgaard, and E. Bjertness, "Is the relationship between smoking and mental health influenced by other unhealthy lifestyle factors? Results from a 3-year follow-up study among adolescents in Oslo, Norway," Journal of Adolescent Health, vol. 45, pp. 609-617, 2009.

[2] S. A. Hiles, A. L. Baker, T. de Malmanche, M. McEvoy, M. Boyle, and J. Attia, "Unhealthy lifestyle may increase later depression via inflammation in older women but not men," Journal of psychiatric research, vol. 63, pp. 65-74, 2015.

[3] W. W. Lee, K. Choi, R. W. Yum, S. Doris, and S. Chair, "Effectiveness of motivational interviewing on lifestyle modification and health outcomes of clients at risk or diagnosed with cardiovascular diseases: A systematic review," International journal of nursing studies, vol. 53, pp. 331-341, 2016.

[4] P. Scarborough, S. Allender, M. Rayner, and M. Goldacre, "An index of unhealthy lifestyle is associated with coronary heart disease mortality rates for small areas in England after adjustment for deprivation," Health \& place, vol. 17, pp. 691-695, 2011.

[5] H. A. Whiteford, L. Degenhardt, J. Rehm, A. J. Baxter, A. J. Ferrari, H. E. Erskine, et al., "Global burden of disease attributable to mental and substance use disorders: findings from the Global Burden of Disease Study 2010," The Lancet, vol. 382, pp. 1575-1586, 2013.

[6] S. B. Wyatt, K. P. Winters, and P. M. Dubbert, "Overweight and obesity: prevalence, consequences, and causes of a growing public health problem," The American journal of the medical sciences, vol. 331, pp. 166-174, 2006.

[7] P. E. Petersen, "The World Oral Health Report 2003: continuous improvement of oral health in the 21st century-the approach of the WHO Global Oral Health Programme," Community Dentistry and oral epidemiology, vol. 31, pp. 3-24, 2003.

[8] A. C. Kuijsten, "Changing family patterns in Europe: A case of divergence?," European Journal of Population/Revue Européenne de Démographie, vol. 12, pp. 115-143, 1996.

[9] A. Rindfleisch, J. E. Burroughs, and F. Denton, "Family structure, materialism, and compulsive consumption," Journal of consumer research, pp. 312-325, 1997.

[10] W. IJsselsteijn, J. van Baren, and F. van Lanen, "Staying in touch: Social presence and connectedness through synchronous and asynchronous communication media," HumanComputer Interaction: Theory and Practice (Part II), vol. 2, pp. 924-928, 2003. 
[11] K. Kuwabara, T. Watanabe, T. Ohguro, Y. Itoh, and Y. Maeda, "Connectedness oriented communication: Fostering a sense of connectedness to augment social relationships," in Applications and the Internet, 2002.(SAINT 2002). Proceedings. 2002 Symposium on, 2002, pp. 186-193.

[12] D. Haber, Health Care for an Aging Society: Cost-Conscious Community Care and Self-Care Approaches: Taylor \& Francis, 2014.

[13] M. Weiser, "Some computer science issues in ubiquitous computing," Communications of the ACM, vol. 36, pp. 75-84, 1993.

[14] I. M. Pires, N. M. Garcia, N. Pombo, and F. Flórez-Revuelta, "From Data Acquisition to Data Fusion: A Comprehensive Review and a Roadmap for the Identification of Activities of Daily Living Using Mobile Devices," Sensors, vol. 16, p. 184, 2016.

[15] P. Sousa, D. Sabugueiro, V. Felizardo, R. Couto, I. Pires, and N. Garcia, "mHealth Sensors and Applications for Personal Aid," in Mobile Health, ed: Springer, 2015, pp. 265-281.

[16] M. Pantic, A. Pentland, A. Nijholt, and T. S. Huang, "Human computing and machine understanding of human behavior: a survey," in Artifical Intelligence for Human Computing, ed: Springer, 2007, pp. 47-71.

[17] C. Peter, E. Ebert, and H. Beikirch, "A wearable multi-sensor system for mobile acquisition of emotion-related physiological data," in Affective Computing and Intelligent Interaction, ed: Springer, 2005, pp. 691-698.

[18] A. H. Maslow, "A theory of human motivation," Psychological review, vol. 50, p. 370, 1943.

[19] J. O. y Gasset, "Obras completas (Madrid," Revista de Occidente, vol. 4, pp. 1929-1933, 1946.

[20] R. Plutchik, The emotions: University Press of America, 1991.

[21] E. Naone. (2010, 2016-03-10). MIT Technology Review - Google Acquires Social Search Engine Aardvark. Available: https://www.technologyreview.com/s/417473/google-acquiressocial-search-engine-aardvark/

[22] D. Goodwin. (2011, 2016-03-10). Search Engine Watch - Google Kills 10 More Projects, Including Aardvark. Available: Google Kills 10 More Projects, Including Aardvark

[23] European Commision. (2016, 2016-03-10). Personalised coaching for well-being and care of people as they age. Available: http://ec.europa.eu/research/participants/portal/desktop/en/opportunities/h2020/topics/3069sc1-pm-15-2017.html

[24] R. Wang, F. Chen, Z. Chen, T. Li, G. Harari, S. Tignor, X. Zhou, D. Ben-Zeev, A. Campbell. StudentLife: assessing mental health, academic performance and behavioral trends of college students using smartphones. In Proceedings of the 2014 ACM International Joint Conference on Pervasive and Ubiquitous Computing (UbiComp '14). ACM, New York, NY, USA, 3-14. DOI=http://dx.doi.org/10.1145/2632048.2632054 